\title{
Supporting Information for \\ Theoretical Analysis of Optical Absorption Spectra of Parallel Nanowire Dimers and Dolmen Trimers
}

Pratima Pandeya ${ }^{\mathrm{a}}$ and Christine M. Aikens ${ }^{\mathrm{a}}$,

a) Department of Chemistry, Kansas State University, Manhattan, KS 66506, USA

* cmaikens@ksu.edu; 1-785-532-0954

Table S1. Coordinates of $\mathrm{Ag}_{4}, \mathrm{Ag}_{6}$ and $\mathrm{Ag}_{10}$ monomers

$\mathrm{Ag}_{4}$ :

1.Ag $\quad 0.000000 \quad 0.000000 \quad-1.373754$

2.Ag $\quad 0.000000 \quad 0.000000 \quad 1.373754$

3.Ag $\quad 0.000000 \quad 0.000000 \quad-3.997090$

4.Ag $\quad 0.000000 \quad 0.000000 \quad 3.997090$

$\operatorname{Ag}_{6}:$

1.Ag $\quad 0.0000000 \quad 0.0000000 \quad 6.6903889$

2.Ag $\quad 0.0000000 \quad 0.0000000 \quad 4.0636955$

$\begin{array}{llll}3 . \mathrm{Ag} & 0.0000000 & 0.0000000 & 1.3280370\end{array}$

$\begin{array}{lllll}4 . \mathrm{Ag} & 0.0000000 & 0.0000000 & -1.3280370\end{array}$

5.Ag $\quad 0.0000000 \quad 0.0000000 \quad-4.0636955$

6.Ag $\quad 0.0000000 \quad 0.0000000 \quad-6.6903889$

$\begin{array}{rrrr}\mathrm{Ag}_{10}: & & & \\ 1 . \mathrm{Ag} & 0.000000 & 0.000000 & 1.334961 \\ 2 . \mathrm{Ag} & 0.000000 & 0.000000 & -1.334961 \\ 3 . \mathrm{Ag} & 0.000000 & 0.000000 & 4.049779 \\ 4 . \mathrm{Ag} & 0.000000 & 0.000000 & -4.049779 \\ 5 . \mathrm{Ag} & 0.000000 & 0.000000 & 6.711155 \\ 6 . \mathrm{Ag} & 0.000000 & 0.000000 & -6.711155 \\ 7 . \mathrm{Ag} & 0.000000 & 0.000000 & 9.440900 \\ 8 . \mathrm{Ag} & 0.000000 & 0.000000 & -9.440900 \\ 9 . \mathrm{Ag} & 0.000000 & 0.000000 & 12.067917 \\ 10 . \mathrm{Ag} & 0.000000 & 0.000000 & -12.067917\end{array}$


Ag6 excitation spectrum

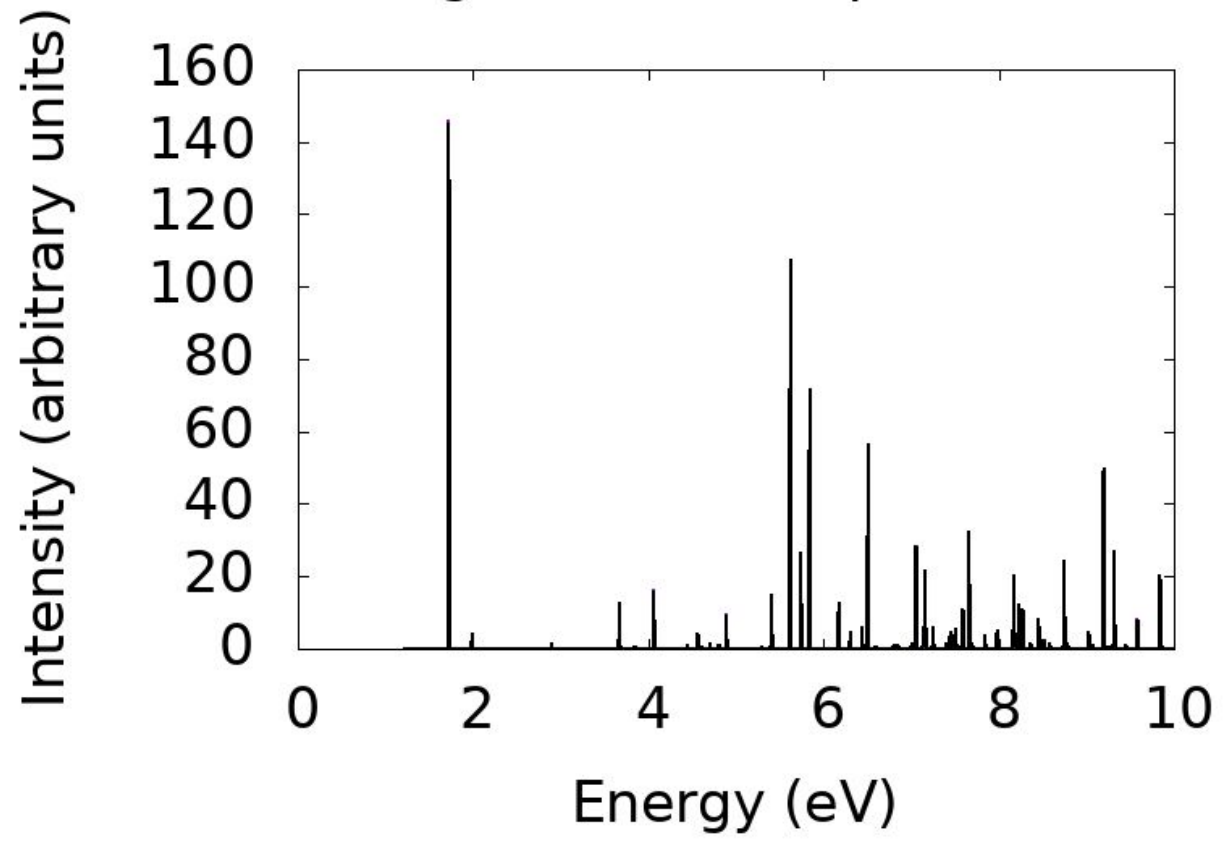

Figure S1. Absorption spectra of $\mathrm{Ag}_{6}$ monomer $(\mathrm{FWHM}=0.01)$.

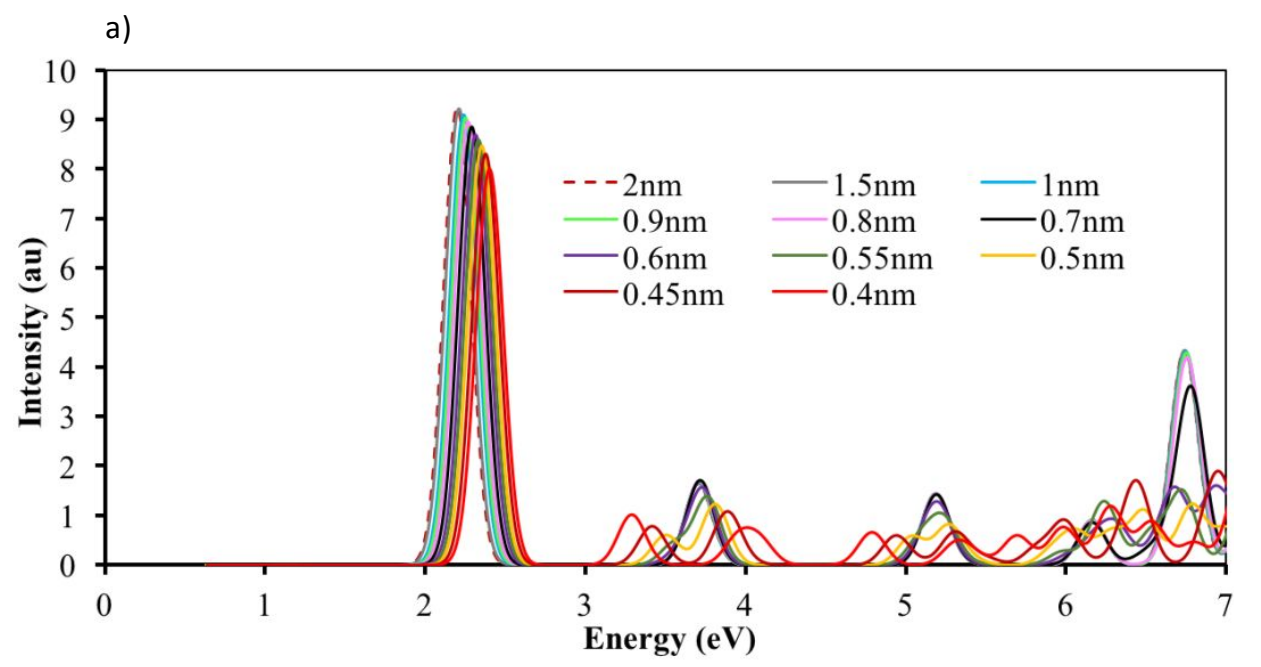


b)

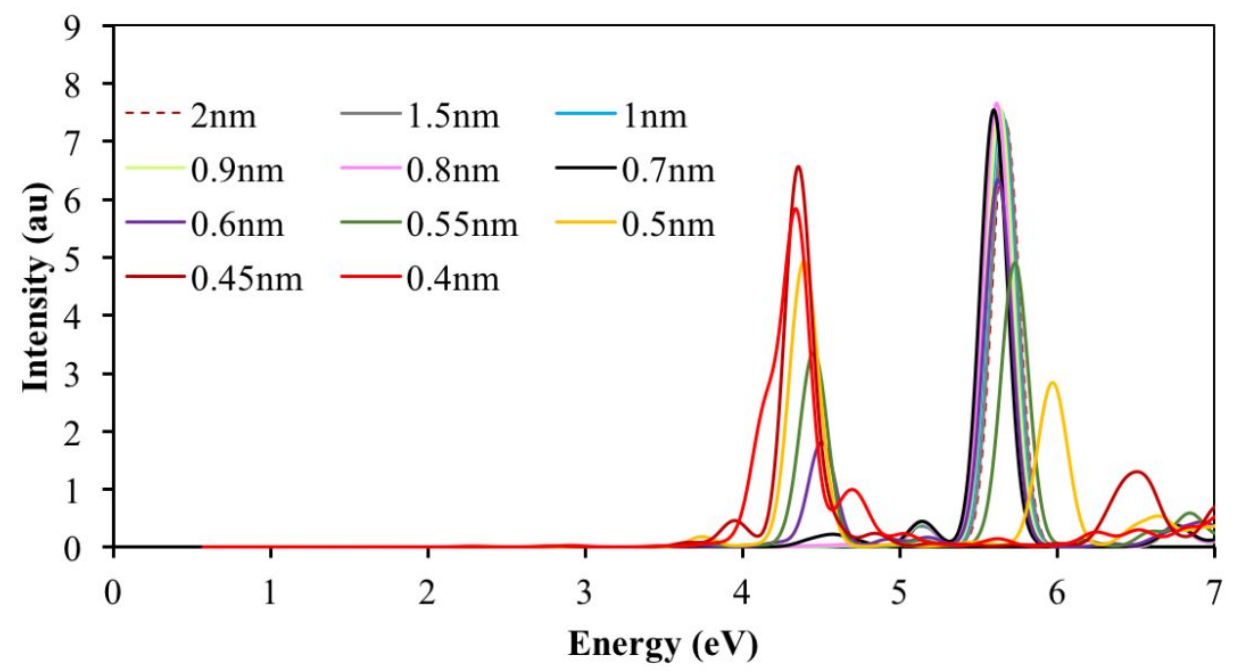

c)

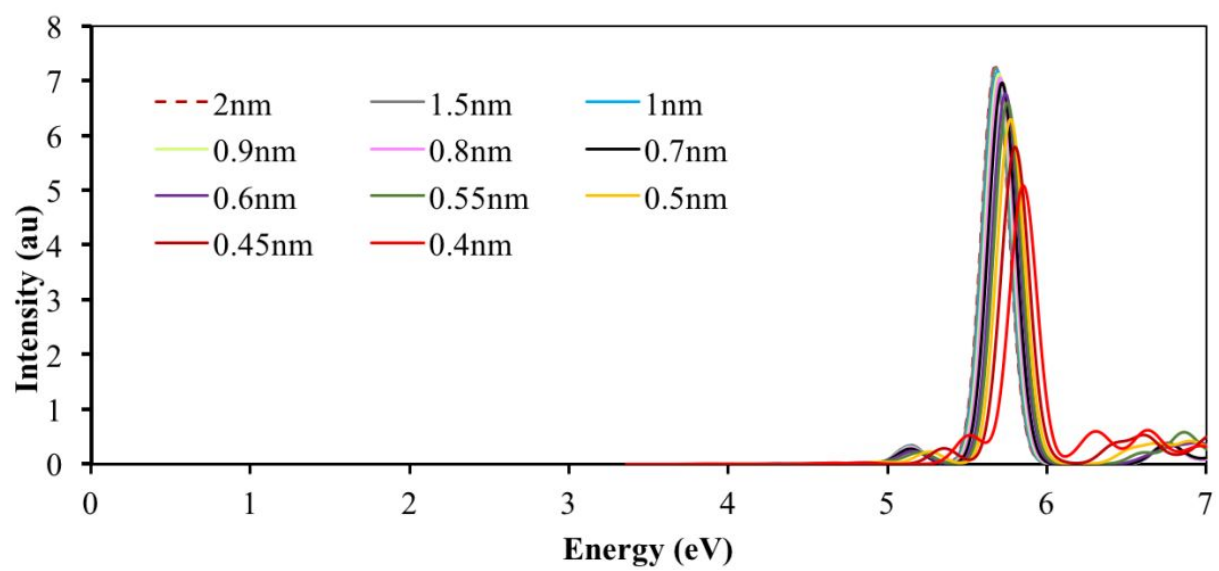

Figure S2. Absorption spectra for $\mathrm{Ag}_{4}$ dimer at different inter-particle separations and for different excited state symmetry representations: a) $B_{1 u}(z$-polarized $)$, b) $B_{2 u}(y$-polarized $)$ and c) $B_{3 u}(x$-polarized). 
a)
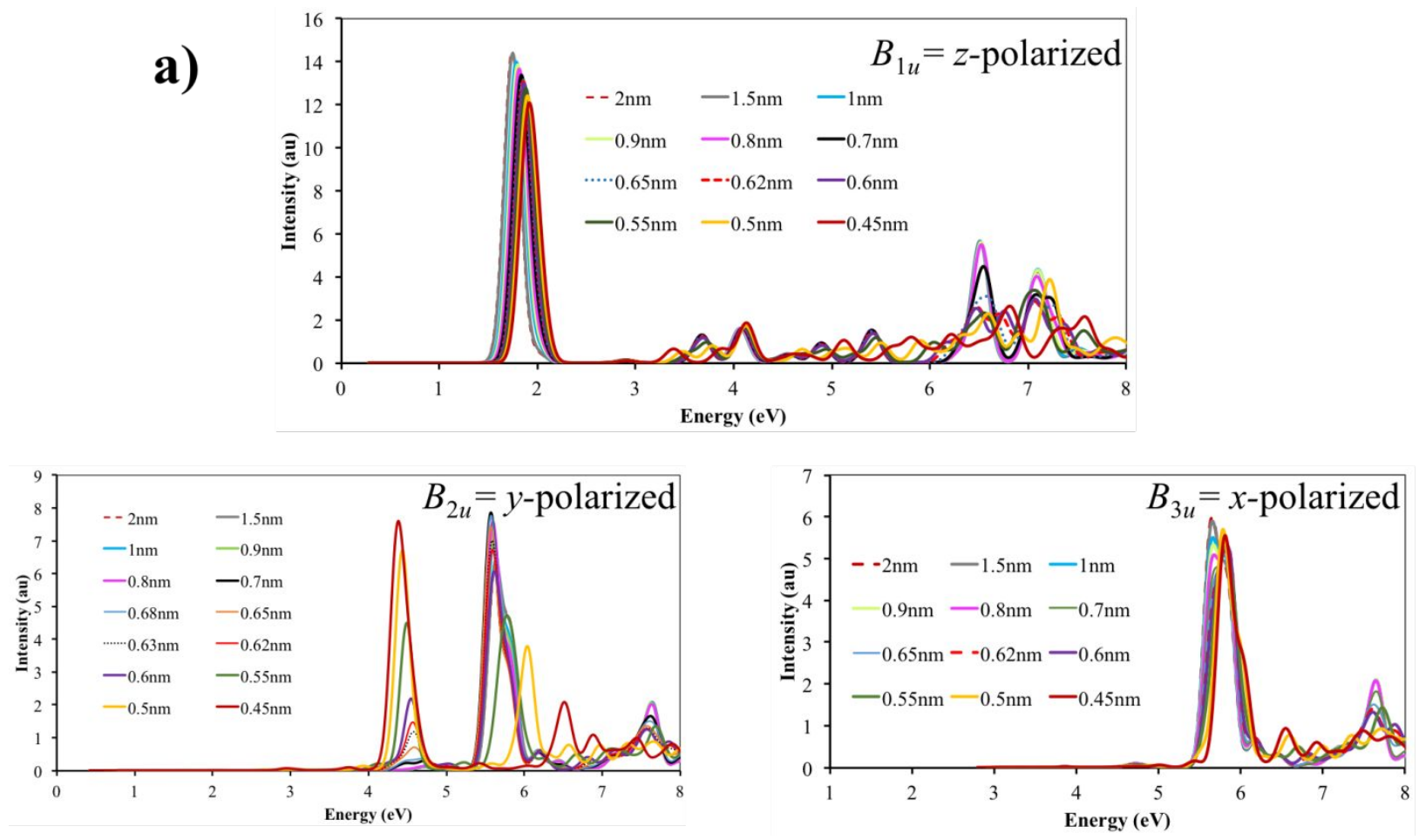

b)
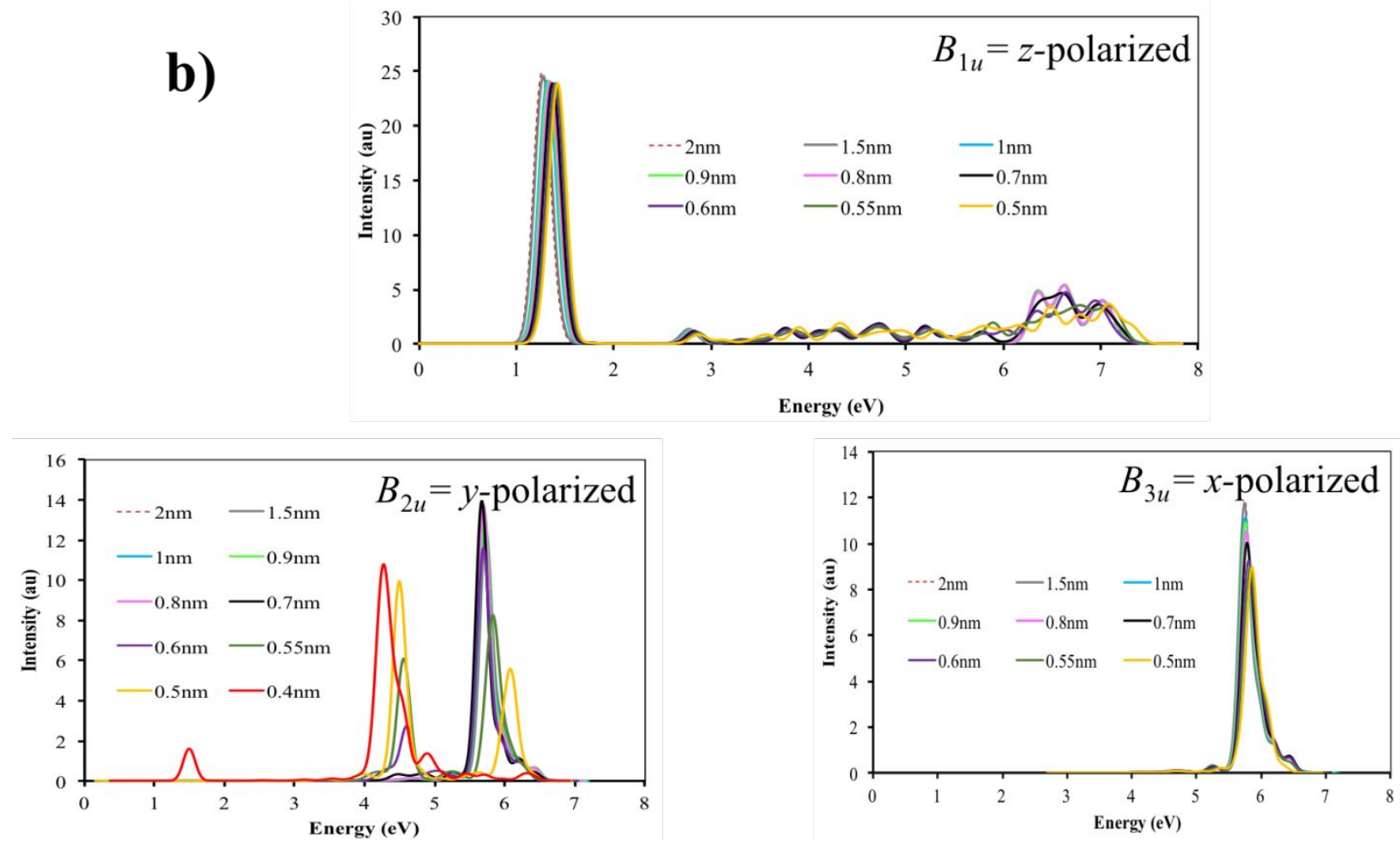

Figure S3. Absorption spectra at different inter-particle separations and for different excited state symmetry representations of (a) $\mathrm{Ag}_{6}$ dimer (b) $\mathrm{Ag}_{10}$ dimer. 


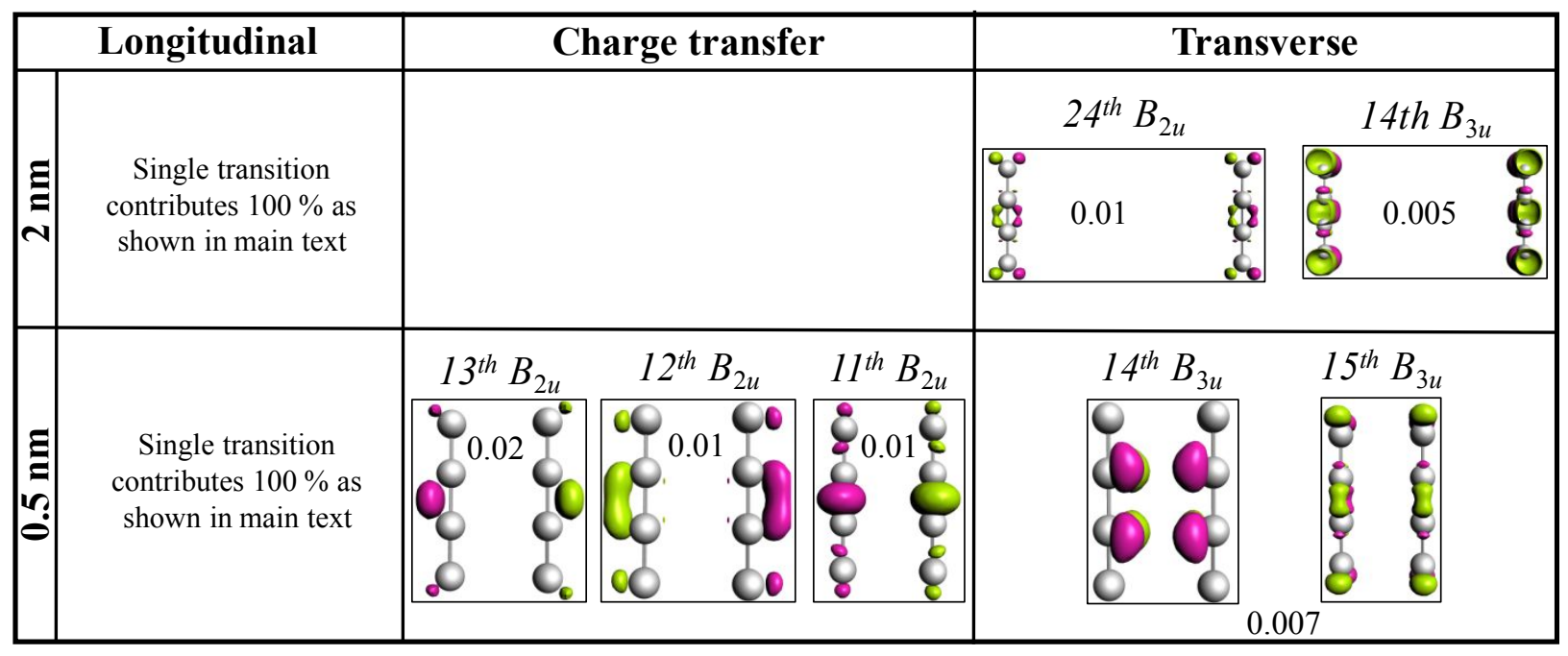

\begin{tabular}{|c|c|c|c|}
\hline $2 \mathrm{~nm}$ & State & Energy (eV) & Oscillator strength (a.u.) \\
\hline Longitudinal & $2^{\text {nd }} B_{1 u}$ & 2.2015 & 1.9706 \\
\hline Transverse & $12^{\text {th }} B_{3 u}$ & 5.6757 & 1.5138 \\
& $14^{\text {th }} B_{3 u}$ & 5.7679 & 0.0607 \\
& $22^{\text {nd }} B_{2 u}$ & 5.6683 & 1.5331 \\
& $24^{\text {th }} B_{2 u}$ & 5.7676 & 0.0527 \\
\hline $0.5 \mathrm{~nm}$ & & & \\
\hline Longitudinal & $2^{\text {nd }} B_{1 u}$ & 2.3548 & 1.8022 \\
\hline Charge transfer & $10^{\text {th }} B_{2 u}$ & 4.3771 & 0.87270 \\
& $13^{\text {th }} B_{2 u}$ & 4.4706 & 0.22687 \\
& $12^{\text {th }} B_{2 u}$ & 4.4527 & 0.03745 \\
& $11^{\text {th }} B_{2 u}$ & 4.4149 & 0.01117 \\
\hline Transverse & $26^{\text {th }} B_{2 u}$ & 5.9284 & 0.28505 \\
& $27^{\text {th }} B_{2 u}$ & 6.0051 & 0.37977 \\
& $13^{\text {th }} B_{3 u}$ & 5.7712 & 1.3136 \\
& $14^{\text {th }} B_{3 u}$ & 5.8594 & 0.02784 \\
& $15^{\text {th }} B_{3 u}$ & 5.9054 & 0.02850 \\
\hline
\end{tabular}

Figure S4. Transition electron densities of weaker excitations (shown in black in the table) that lie close in energy to the stronger excitations that have been discussed in the main text (shown in red in the table). The table shows the oscillator strength of each excited state. 
a)
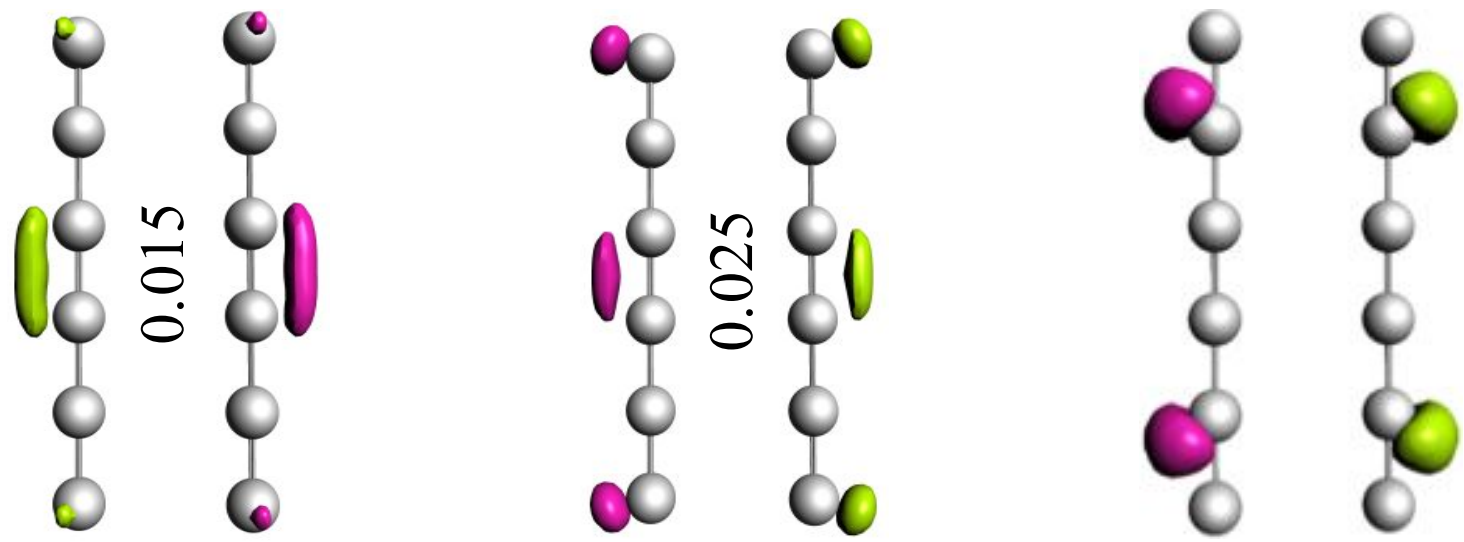

b)
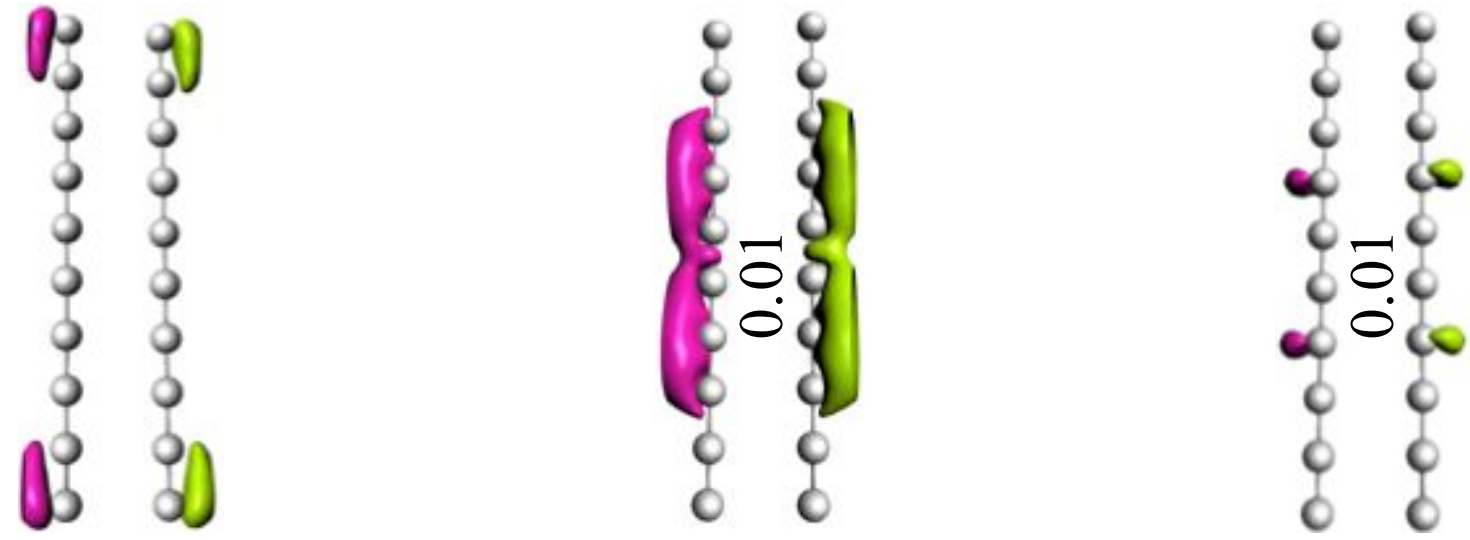

Figure S5. Transition densities for the charge transfer peak of a) $\mathrm{Ag}_{6}$ dimer at $0.5 \mathrm{~nm}$ separation, and b) $\mathrm{Ag}_{10}$ dimer at $0.5 \mathrm{~nm}$ separation. Transition densities are drawn with an iso-value of 0.02 unless stated. 

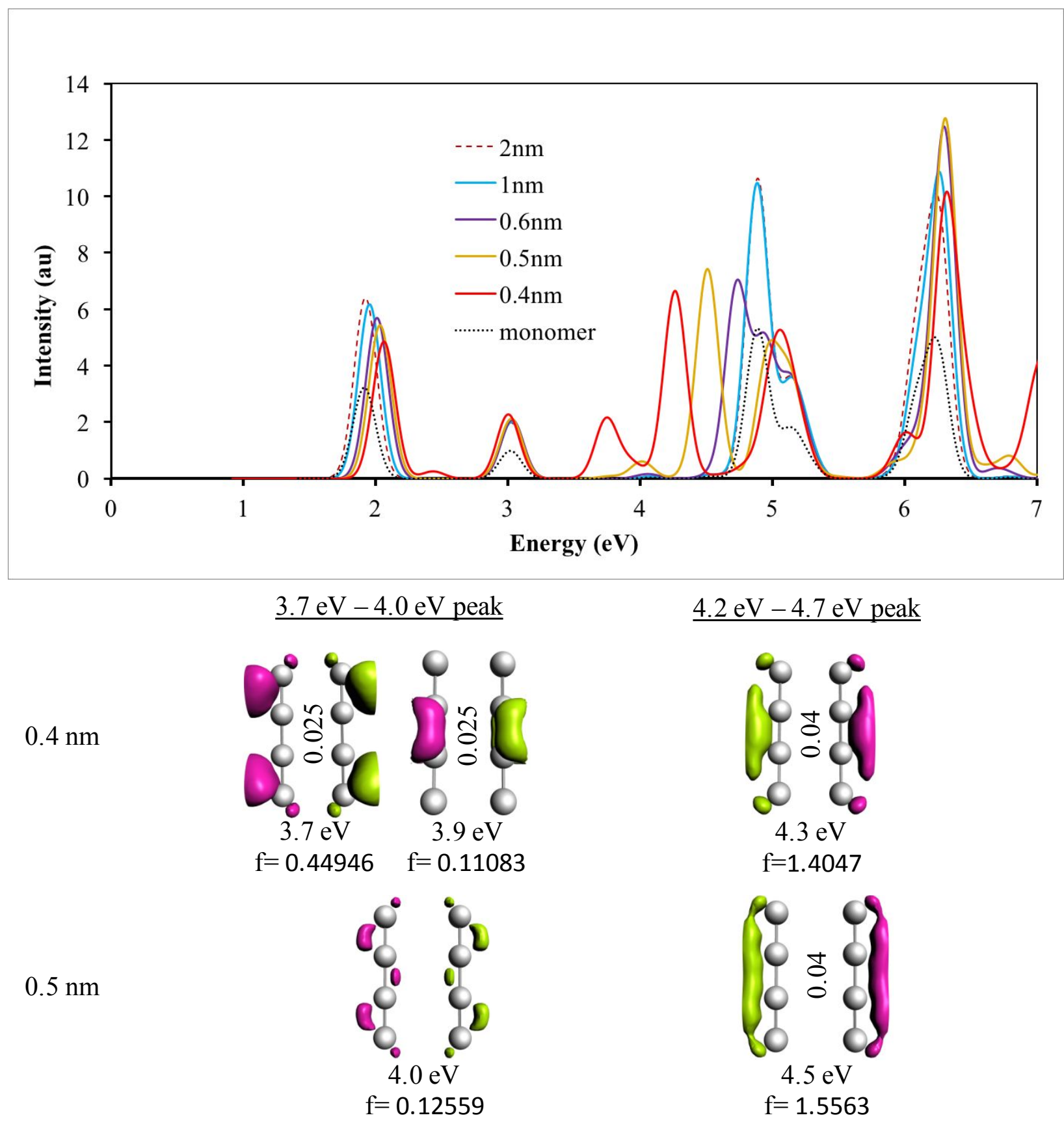

$0.6 \mathrm{~nm}$

$\underline{4.2 \mathrm{eV}-4.7 \mathrm{eV} \text { peak }}$

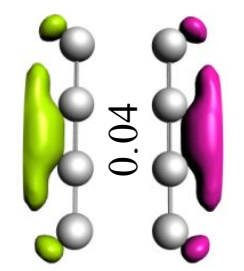

$4.3 \mathrm{eV}$

$\mathrm{f}=1.4047$

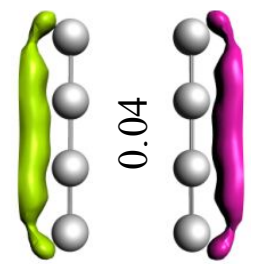

$4.5 \mathrm{eV}$

$\mathrm{f}=1.5563$

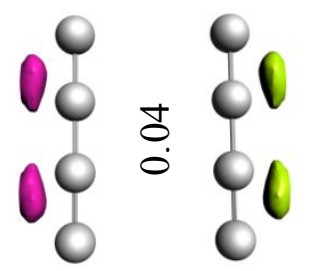

$4.7 \mathrm{eV}$

$\mathrm{f}=1.4458$

Figure S6. Spectra obtained with TDHF at different monomer separations; transition density plots for the newly formed charge-transfer peaks. 
a)

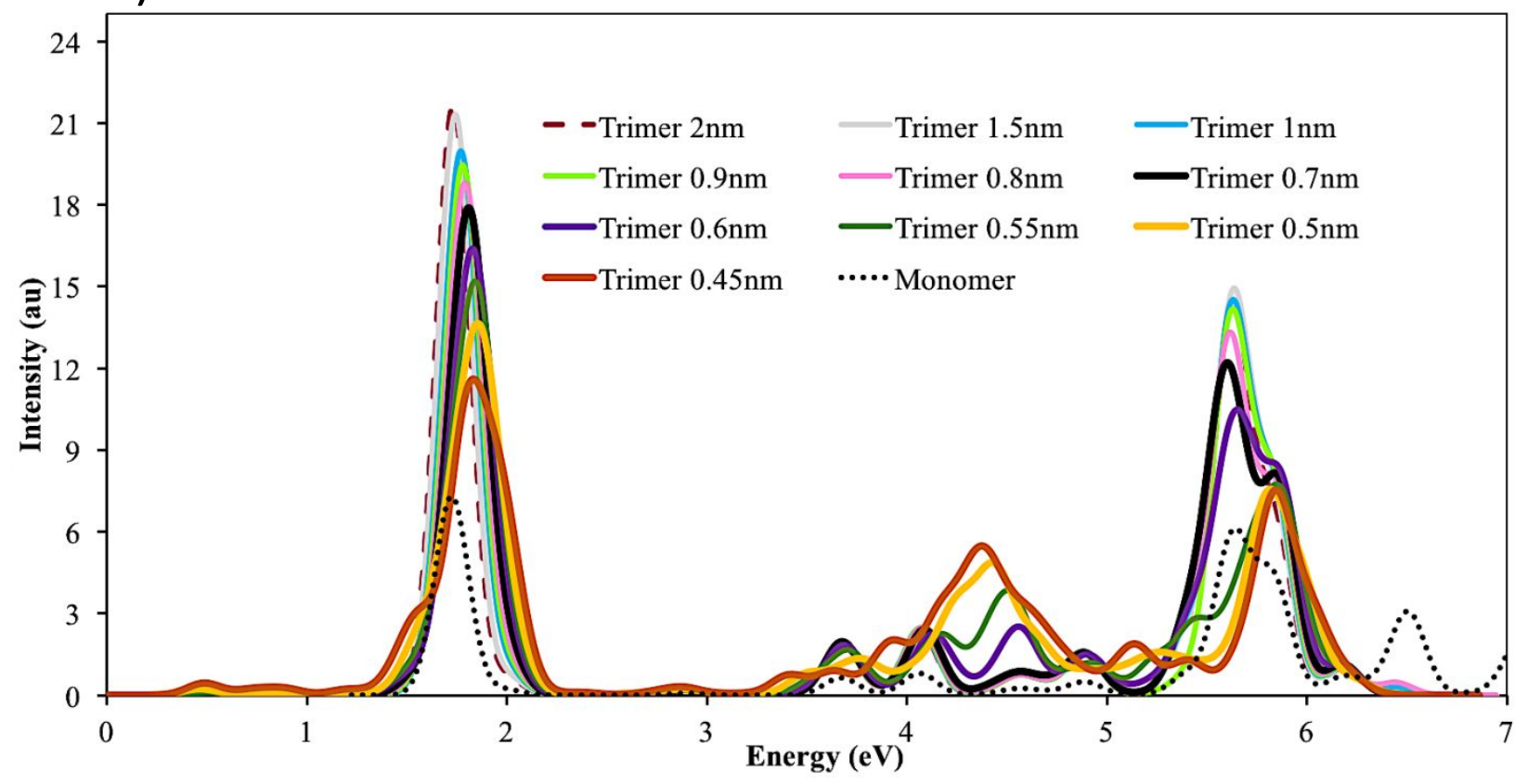

b)

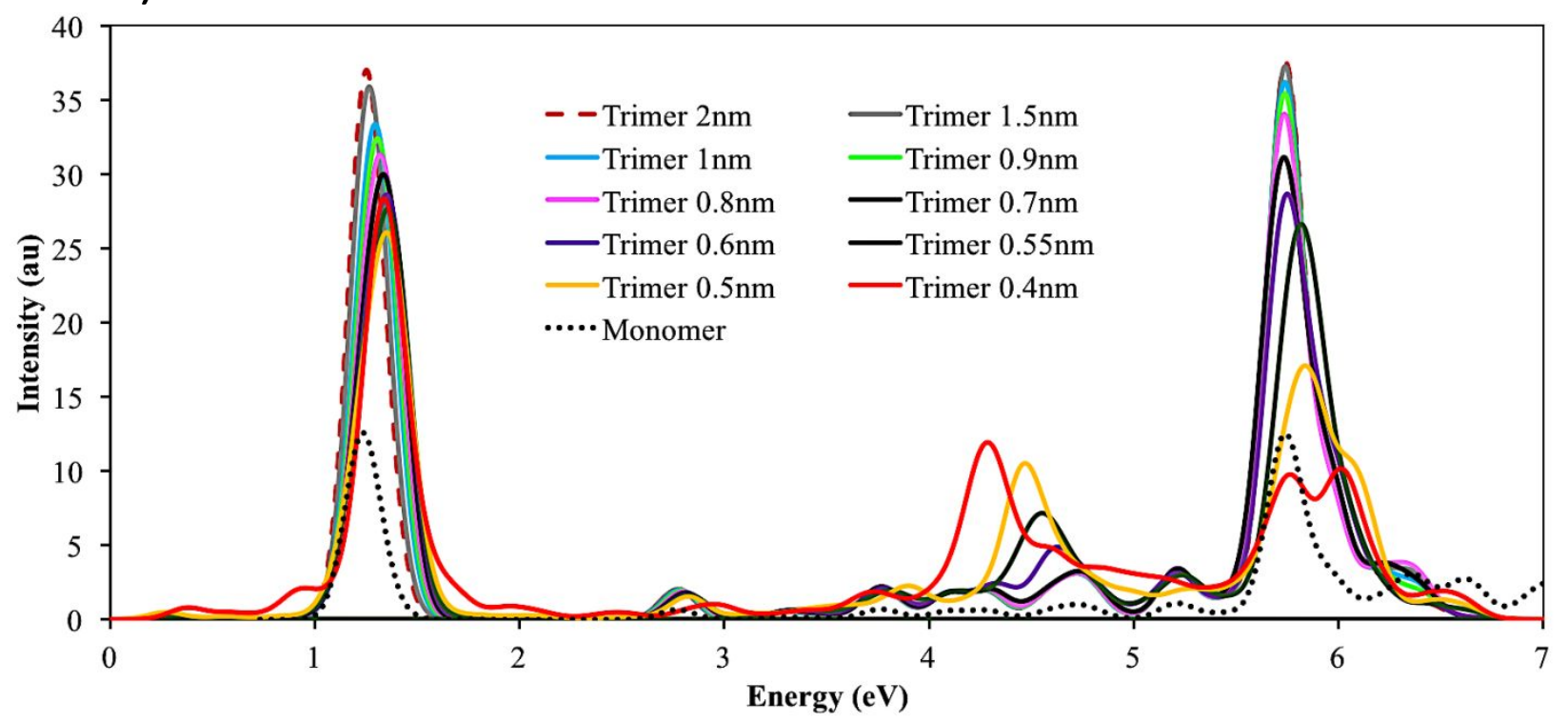

Figure S7. Absorption spectra of a) $\mathrm{Ag}_{6}$ and b) $\mathrm{Ag}_{10}$ trimers at different inter-particle separation. 

a)

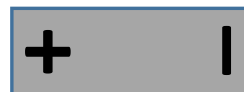
$y$-polarized
(capping nanowire)

b)

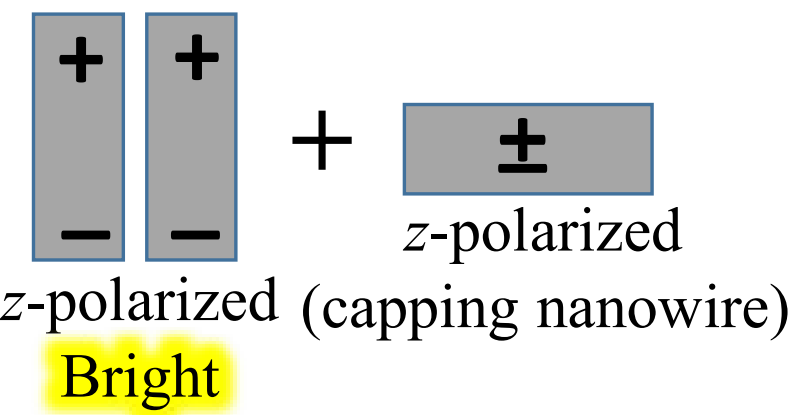

Figure S8. Plasmon interaction diagram showing different possibilities for the longitudinal peak of the trimer.

a)
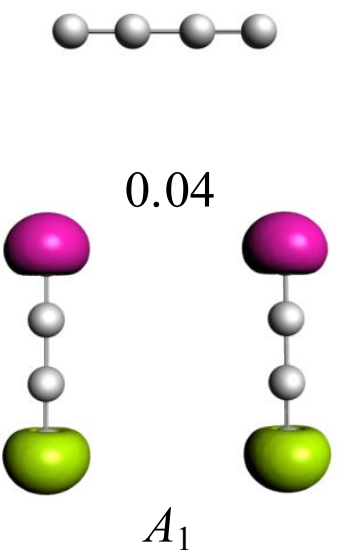
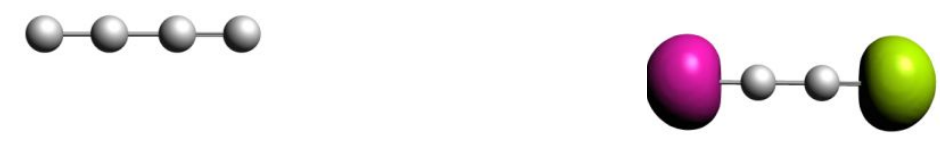

0.04

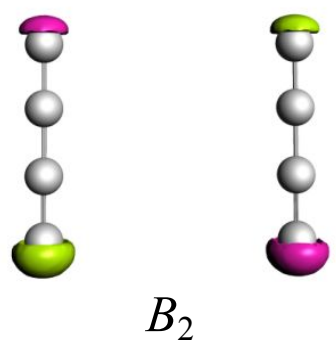

0.045

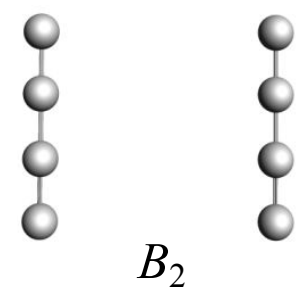


b)

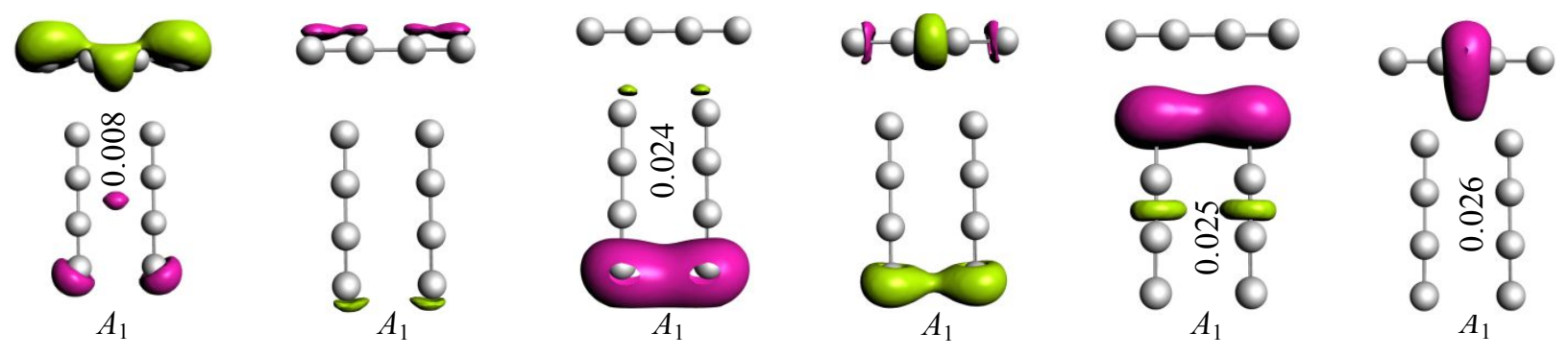

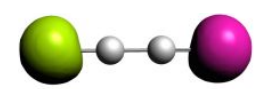

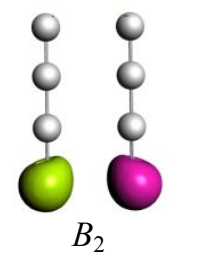

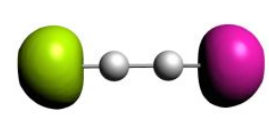

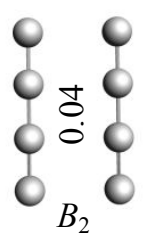
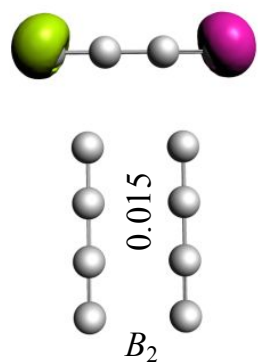
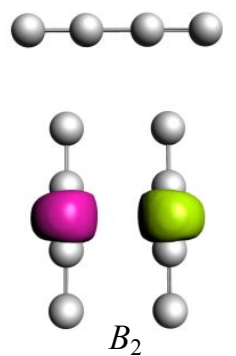

Figure S9. Transition electron densities for the longitudinal peak of the trimer at a) $1 \mathrm{~nm}$ separation, and b) $0.45 \mathrm{~nm}$ separation.

a)

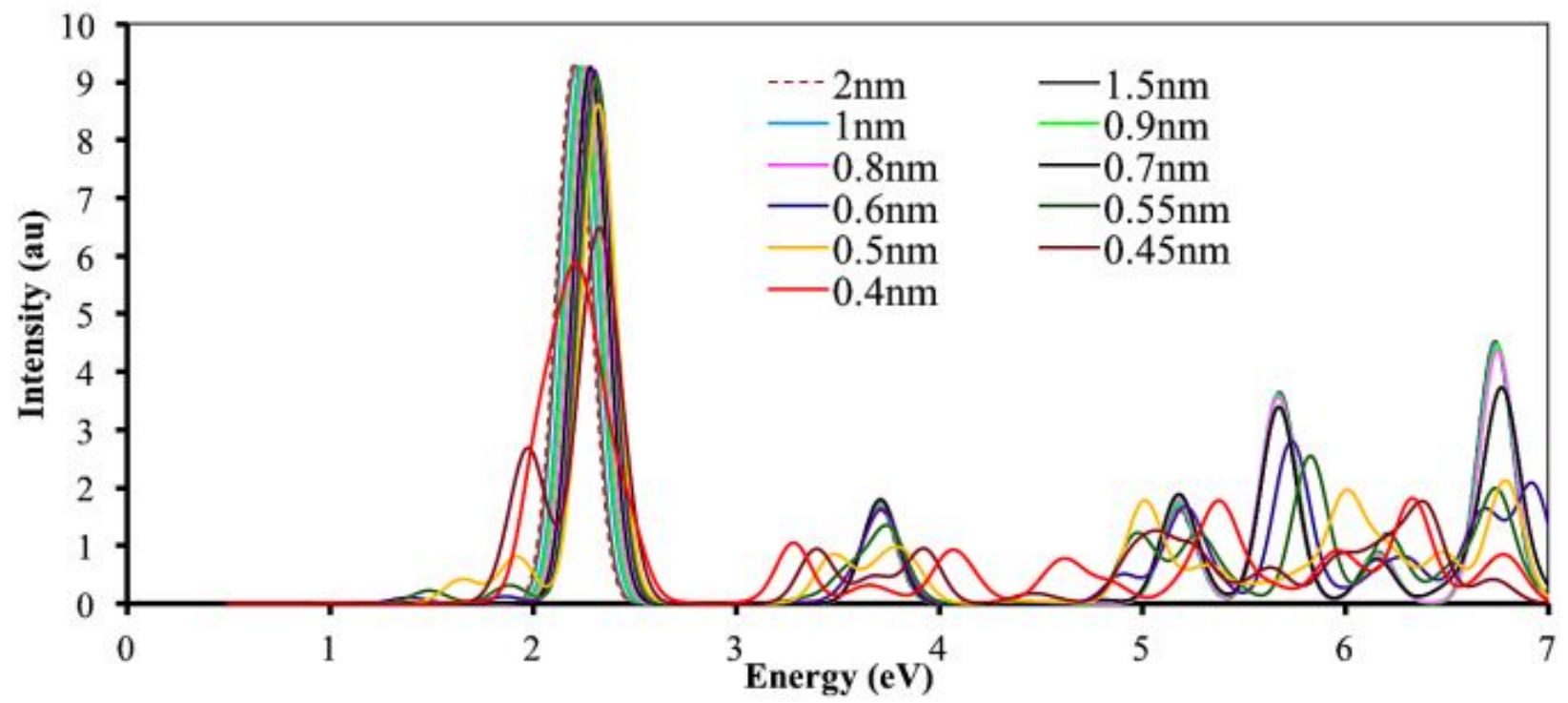


b)

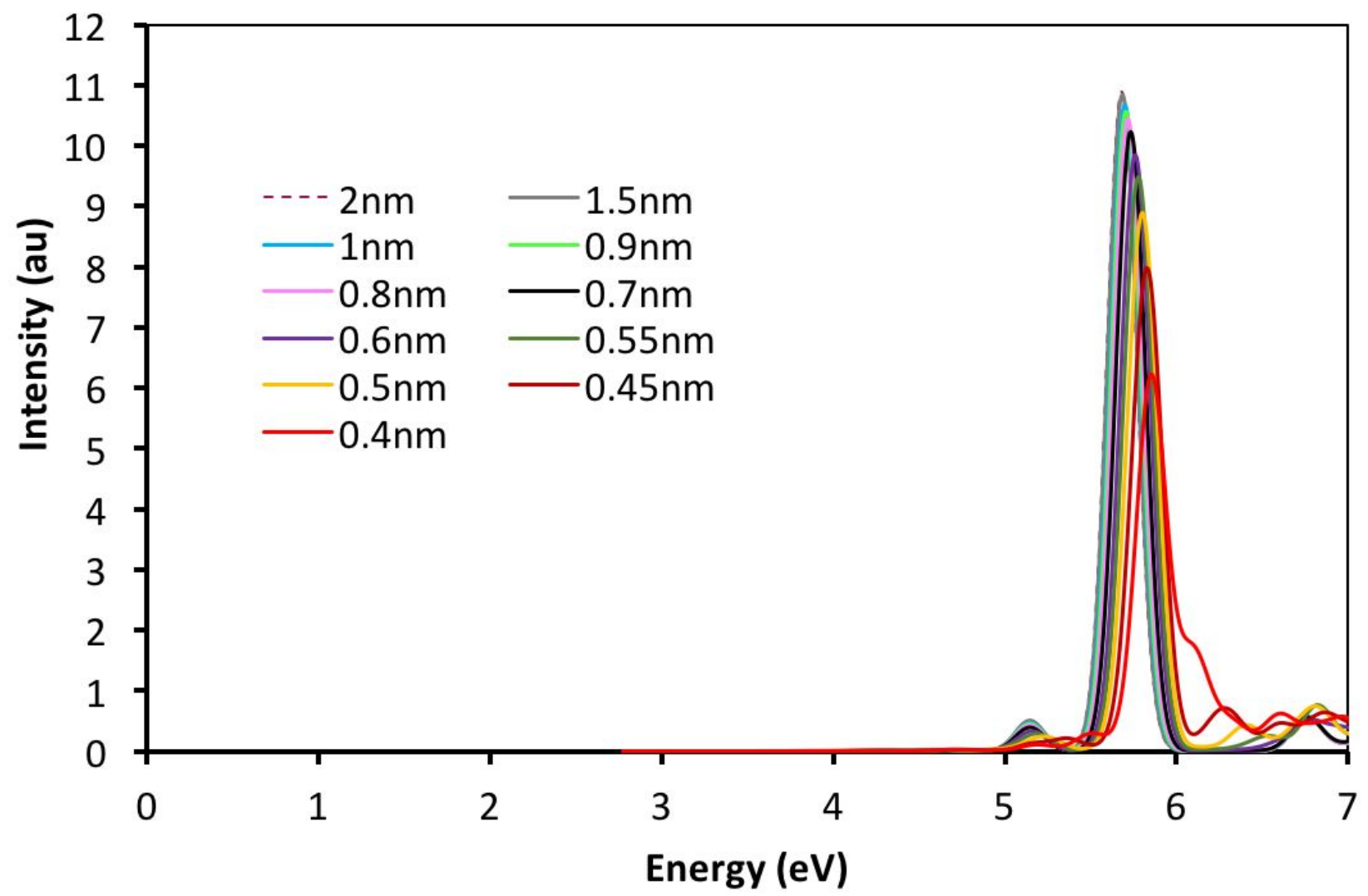

c)

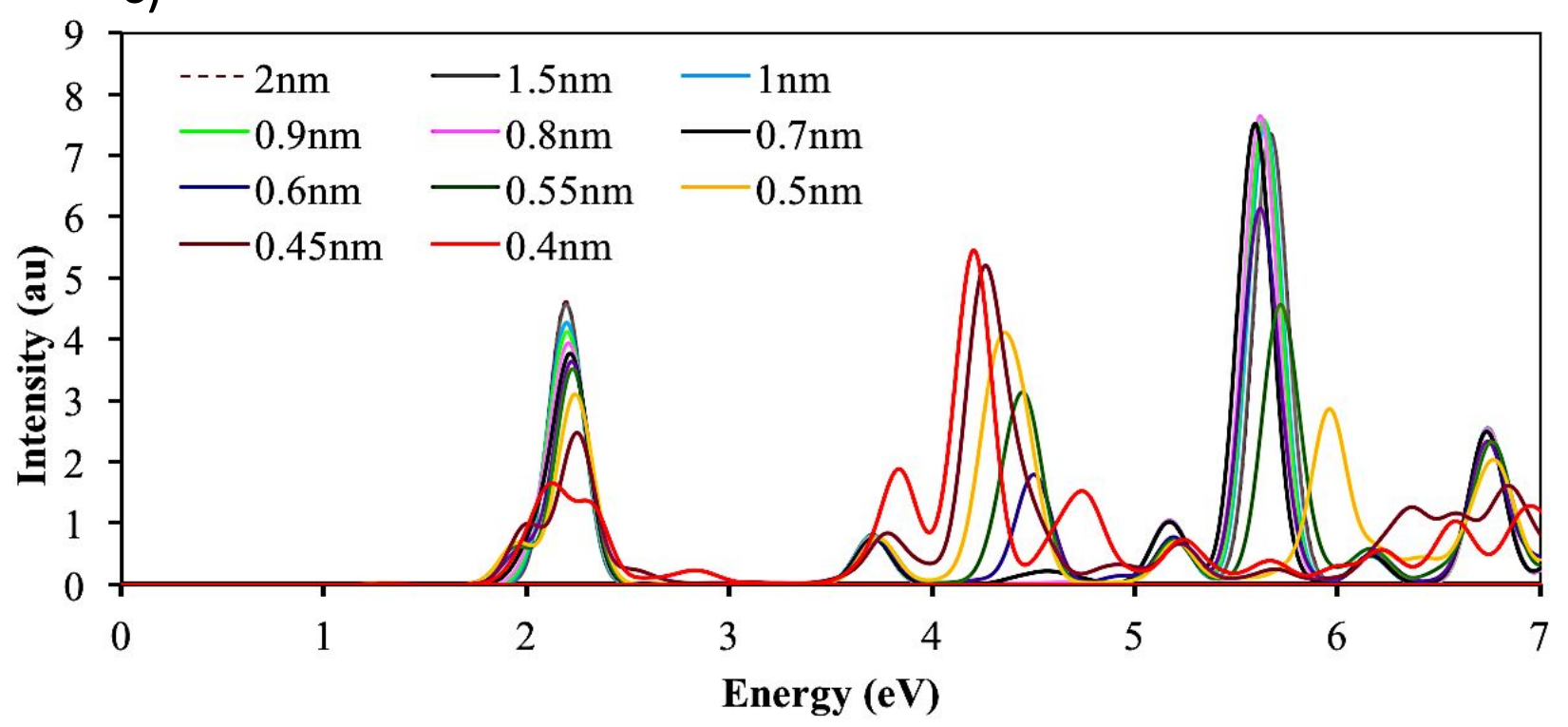

Figure S10. Absorption spectra for $\mathrm{Ag}_{4}$ trimer at different inter-particle separations and for different excited state symmetry representations: a) $A_{1}$, b) $B_{1}$ and c) $B_{2}$. 